\title{
Calculation of Spark Breakdown or Corona Starting Voltages in Nonuniform Fields
}

\section{Pedersen, A.}

Published in:

IEEE Transactions on Power Systems

Link to article, DOI:

10.1109/TPAS.1967.291836

Publication date:

1967

Document Version

Publisher's PDF, also known as Version of record

Link back to DTU Orbit

Citation (APA):

Pedersen, A. (1967). Calculation of Spark Breakdown or Corona Starting Voltages in Nonuniform Fields. IEEE Transactions on Power Systems, 86(2), 200-206. https://doi.org/10.1109/TPAS.1967.291836

\section{General rights}

Copyright and moral rights for the publications made accessible in the public portal are retained by the authors and/or other copyright owners and it is a condition of accessing publications that users recognise and abide by the legal requirements associated with these rights.

- Users may download and print one copy of any publication from the public portal for the purpose of private study or research.

- You may not further distribute the material or use it for any profit-making activity or commercial gain

- You may freely distribute the URL identifying the publication in the public portal

If you believe that this document breaches copyright please contact us providing details, and we will remove access to the work immediately and investigate your claim. 


\title{
Calculation of Spark Breakdown or Corona Starting Voltages in Nonuniform Fields
}

\author{
A. PEDERSEN, SENIOR MEMBER, IEEE
}

\begin{abstract}
The processes leading to a spark breakdown or corona discharge are discussed very briefly. A quantitative breakdown criterion for use in high-voltage design is derived by which spark breakdown or corona starting voltages in nonuniform fields can be calculated. The criterion is applied to the sphere gap, and it is shown how it can give a very detailed and accurate description of known breakdown characteristics.
\end{abstract}

\section{INTRODUCTION}

A KNOWLEDGE of spark breakdown or corona starting voltages for various gap geometries is essential when designing many types of high-voltage apparatus. A large amount of experimental data is available in standard textbooks on high-voltage engineering [1], [2] and electrical breakdown of gases [3], [4]. Many empirical formulas are available from which breakdown or corona starting field strengths may be calculated. However, empirical formulas are only valid within certain ranges, and extrapolation can lead to large errors. In view of the growing demand for equipment for power transmission at extra-high voltages, it may be of interest to consider the possibilities of applying modern theories of spark breakdown to the design of high-voltage equipment.

The classical Townsend theory [3]-[6] of the growth of ionization is fundamental to any discussion of electrical breakdown of gases. It is generally accepted that this theory can account for the formation of a spark in a uniform field under quasi-static conditions. However, in order to give a detailed description of many observed phenomena of engineering importance, the Townsend theory must be supplemented by the streamer theories of Loeb and Meek [7]; and Raether [8], [9]. Quantitative criteria for breakdown have been proposed based on these theories. These criteria are of considerable importance when discussing the physics of the breakdown. They are, however, of limited value to the high-voltage engineer. The results are not sufficiently accurate, and often they cannot be applied at all, because the necessary physical data are not available. However, in spite of these limitations it is possible on the basis of these theories to formulate a semiempirical quantitative criterion, by which spark breakdown or corona starting voltages in any nonuniform gap of known field distribution can be calculated with an accuracy of a few per-

Paper 31 TP $66-80$, recommended and approved by the Transformers Committee of the IEEE Power Group for presentation at the IEEE Winter Power Meeting, New York, N.Y., January 30February 4, 1966. Manuscript submitted October 25, 1965; made available for printing November 24, 1965.

The author is with the Department of Physics, Technical University of Denmark, Lyngby, Denmark. cent. Attempts in this direction are described in earlier work by Schumann [10], Ver Planck [11], Hutton [12], J $\varnothing$ gensen [13], and Pedersen [14].

The present study is a continuation of the work by Jørgensen and Pedersen. The method described will enable the high-voltage engineer to calculate breakdown voltages or corona starting voltages more reliably than by the rule of thumb methods in common use.

The mechanism of breakdown may depend upon how the electric field is applied. The processes involved in the breakdown of a gap subjected to a carefully smoothed dc voltage may be different from those involved in a breakdown of the same gap when the applied voltage is a steepfronted impulse voltage. This latter type of breakdown is most important from an engineering point of view, and in the following breakdown of this type in air at atmospheric pressure is specially dealt with.

\section{The Townsend Theory}

A gas such as air is normally an almost perfect insulator, but because of the natural background of radioactive and cosmic radiation some electrons and ions will always be present. An applied electric field will, consequently, result in a current, which under normal conditions and low field strengths is very feeble. At higher field strengths the current is greatly increased because of the occurrence of ionizing processes in the gas and at the surface of the negative electrode, for air at atmospheric pressure field strengths higher than $15 \mathrm{kV} / \mathrm{cm}$ are required.

The primary ionizing process in the gas is ionization of a neutral gas molecule by collision with an electron which has been accelerated by the applied field and thus gained the necessary energy. By this process a new electron ion pair is formed. It is a cumulative process and the number of electrons and positive ions grows extremely rapidly by the formation of such electron avalanches.

The positive ions are also accelerated in the field, but they gain considerably less energy than the electrons as they lose too much energy in each collision because of their much larger mass, and it is very unlikely that they can ionize in the gas. They can, however, produce new electrons by bombardment of the surface of the negative electrode. Such a process is called a secondary process. Other important secondary processes are photoelectric emission from the cathode and photoionization in the gas caused by photons originating from excited atoms or from recombination processes.

The growth of the current in a uniform field because of various primary and secondary processes can be written 
as $[3]-[6]$

$$
I=I_{0} \frac{\exp (\alpha d)}{1-\gamma\{\exp (\alpha d)-1\}}
$$

where $I$ is the current, $I_{0}$ is the initial current due solely to external ionizing sources, $d$ is the gap length, $\alpha$ is the number of ionizing collisions for an electron per unit length of path in the direction of the field and is called Townsend's first ionization coefficient, and $\gamma$ is the second Townsend ionization coefficient which represents all the possible secondary processes.

Equation (1) describes a steady state, i.e., the applied voltage must be so low that breakdown does not occur. It cannot, therefore, describe the transient processes which take place during the formation of a spark. It does, however, determine the voltage level at which a uniform field gap breaks down, because breakdown must occur when the current tends towards infinity. This happens when the denominator becomes zero, i.e., breakdown takes place when

$$
\gamma\{\exp (\alpha d)-1\}=1 .
$$

This is Townsend's breakdown criterion. It does not give any information about the temporal growth of the processes leading to breakdown. It is, however, inherent in the Townsend theory that many generations of electron avalanches are required to build up a breakdown.

The second Townsend coefficient $\gamma$ is very sensitive to electrode conditions and gas impurities, and it will only be well defined under carefully controlled laboratory conditions. Equation (2) is, therefore, of little use to the highvoltage design engineer. Schumann [10] has suggested that the Townsend criterion for breakdown in air at atmospheric pressure may be written as

$$
\int_{0}^{d} \alpha d x=k
$$

where $k$ is a constant equal to 20 . Another version of the Townsend criterion which should apply to cathode initiated types of breakdown has been suggested by Ver Planck [11], Hutton, [12] who replaced $k$ in (3) with a function of the field strength at the cathode.

\section{The Streamer Theory}

A Townsend type of breakdown requires a whole sequence of avalanches. For a 1-cm gap in atmospheric air, therefore, formative time lags of several microseconds should be expected. The gap may, however, break down in less than $0.1 \mu \mathrm{s}$. This fact led to the concept of the streamer type of breakdown [7]-[9], which is a breakdown caused by a single electron avalanche. According to the streamer theory the space charge field from the electrons and ions in the head of an avalanche may cause an instability in the development of the avalanche resulting in the formation of fast moving anode and cathode directed streamers from the avalanche head. These streamers form a highly conducting plasma channel across the gap, and the voltage breaks down. The basic mechanism behind the formation of streamers was thought to be photoionization in the gas.

The streamer theory has been much criticized, notably by Llewellyn-Jones [5] and his school, who claim that the Townsend mechanism is sufficient to explain the formation of a spark. This is probably true for the breakdown of an almost uniform gap subjected to a slowly increasing and carefully smoothed dc voltage. For nonuniform fields and gaps subjected to steep-fronted impulse voltages it appears, however, that a single avalanche mechanism, such as the streamer mechanism, is necessary to explain many observed breakdown characteristics. And it is this type of breakdown which is a hazard in the design of high-voltage apparatus.

A satisfactory quantitative criterion for streamer formation has never been formulated. Meek made the plausible assumption that cathode and anode directed streamers would develop when the radial space charge field from the avalanche head becomes of the same order of magnitude as the externally applied field. This leads to the following equation for the breakdown of a nonuniform gap

$$
\alpha_{x} \exp \left\{\int_{0}^{x} \alpha d x\right\}=K E_{x}\{x / \rho\}^{1 / 2} .
$$

In this equation $x$ denotes the critical avalanche length, i.e., the length of the avalanche at the moment when it becomes unstable and streamers are formed. In nonuniform fields $x$ may be shorter than the gap length. $\alpha_{x}$ is the first Townsend ionization coefficient at the avalanche head, $\rho$ is the gas density, and $K$ is a constant. A similar equation was proposed by Raether.

The exponential term is the dominating factor in Meek's equation, and a detailed analysis will show that the exponent should be almost constant and independent of the gap geometry. Meek's equation may, consequently, be written simply as

$$
\int_{0}^{x} \alpha d x=k
$$

where the constant $k$ has a value of about 20 for air at atmospheric pressure. This means that Meek's breakdown criterion, as far as breakdown voltages are concerned, is virtually identical to the Schumann criterion.

If the constant $k$ in Schumann's equation is calculated from measured breakdown voltages in a uniform field, it is found that $k$ is not at all constant but varies between 10 and 45 for gap lengths between 0.1 and $10 \mathrm{~cm}$. The ionization coefficient $\alpha$, however, varies very rapidly with the field strength, as seen in Fig. 1, which is based on measurements by Sanders [15]. Breakdown voltages calculated from $\alpha d=20$ will, therefore, be close to the true values in a uniform field. A detailed analysis of the Schumann criterion by Jørgensen [13] has, however, shown that it is of very limited validity when applied to various nonuniform fields. Jørgensen also showed that a considerable improvement is obtained if the constant $k$ is replaced by a function of the gap length. 


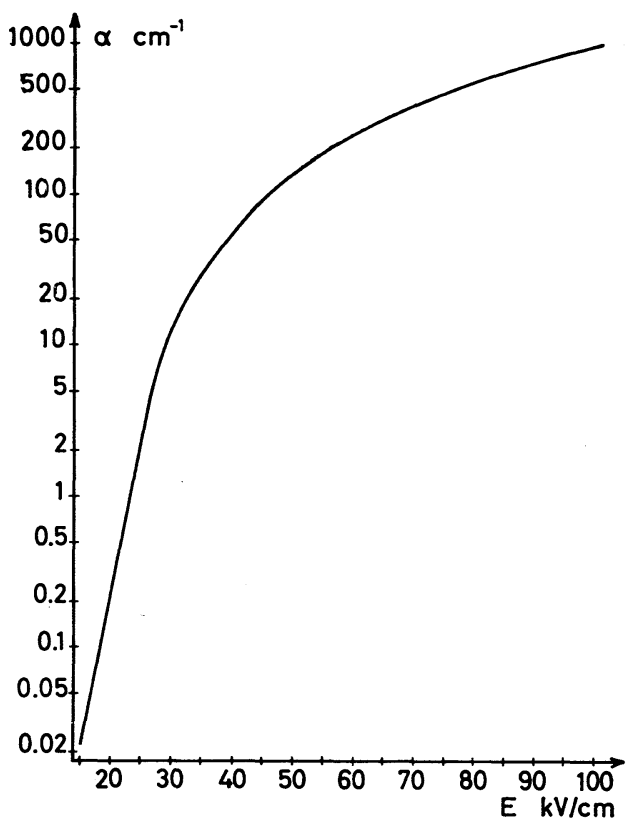

Fig. 1. Townsend's ionization coefficient for air at $760 \mathrm{~mm} \mathrm{Hg}$ and $20^{\circ} \mathrm{C}$.

\section{A General Criterion for the Formation of Streamers}

The shortcomings of Meek's equation are caused by the difficulties involved in a quantitative formulation of the streamer concept. It was not even possible to include any quantity depending on photoionization in the gas, which was held responsible for the formation of streamers. Had it been possible to take this and other probable processes into account, it is plausible that the equation determining breakdown or formation of streamers in air would be of the following form

$$
\alpha_{x} \exp \left\{\int_{0}^{x} \alpha d x\right\}=G\left\{x, \rho, f\left(E_{x}\right), \mu, \% \mathrm{H}_{2} \mathrm{O}, \ldots\right\}
$$

where $G$ is an unknown function of the critical avalanche length $x$, air density $\rho$, field distribution $f\left(E_{x}\right)$, photoization in the gas $\mu$, humidity percent $\mathrm{H}_{2} \mathrm{O}$, and other possible variables. Earlier work has, however, shown that $x$ and $\rho$ are the dominating variables in a function of this type [13], [14]. A good approximation is, therefore, obtained by neglecting all other variables, and the breakdown equation then becomes

$$
\alpha_{x} \exp \left\{\int_{0}^{x} \alpha d x\right\}=G\{x, \rho\}
$$

For air at atmospheric pressure this breakdown equation may be written as

$$
\ln \left(\alpha_{x}\right)+\int_{0}^{x} \alpha d x=g(x)
$$

where $\left(\alpha_{x}\right)$ is the numerical value of $\alpha$ at the avalanche head. In a uniform field $x$ is equal to the gap length and

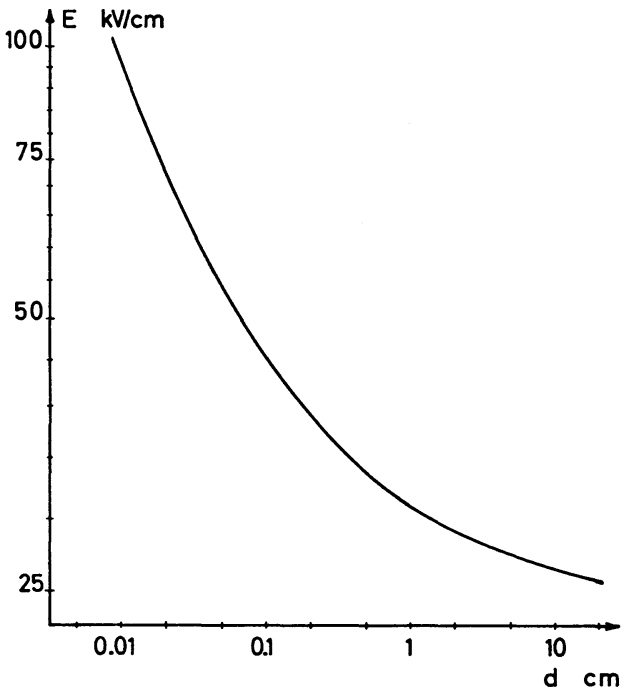

Fig. 2. Breakdown field strengths in air at $760 \mathrm{~mm} \mathrm{Hg}$ and $20^{\circ} \mathrm{C}$.

$\alpha$ is constant. The breakdown equation then becomes

$$
\ln (\alpha)+\alpha x=g(x) .
$$

This means that numerical values of the function $g(x)$ can be found by calculating the left-hand side of (9) from measured breakdown field strengths in a uniform field [16] shown in Fig. 2. When calculating $g(x)$ in this way the field distortion caused by space charges in the avalanche head is neglected. This is, however, also the case when (8) is applied to nonuniform fields, and the error introduced by neglecting the field distortion is thereby counteracted to some extent.

The voltage found by solving (8) is the minimum voltage required for the formation of streamers. In highly nonuniform fields this will be the corona starting voltage and not the breakdown voltage. In such cases the actual flashover voltage cannot be calculated, but may often be estimated quite accurately from rod gap data.

\section{Application of the Breakdown Equation to the. SPHERE GaP}

Sphere gaps are used in high-voltage testing as a standard for high-voltage measurements, and a considerable amount of experimental data on details in breakdown characteristics is available for this field geometry. The sphere gap is, therefore, very suitable as an illustration of the capability of the breakdown equation. Applied to the sphere gap (8) will not only give breakdown voltages which are within about two percent of the standard values, it will also explain known details in the breakdown characteristics.

A $25 \mathrm{~cm}$ diameter sphere gap with one sphere earthed, and an applied voltage of negative polarity is considered. In this case the electron avalanche leading to breakdown will start at the surface of the negative high-voltage sphere. To find Townsend's $\alpha$, the field distribution must be known. This can be calculated by means of the method of images [13], [17], [18]. Let $D$ denote the sphere diameter, 


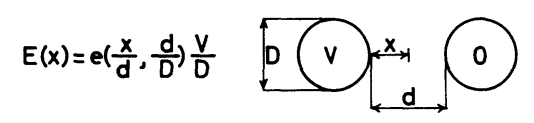

\begin{tabular}{|c|c|c|c|c|c|}
\hline \multicolumn{6}{|c|}{$e\left(\frac{x}{d}, \frac{d}{D}\right)$} \\
\hline$d / d$ & 0.2 & 0.4 & 0.6 & 0.8 & 1.0 \\
\hline 0.0 & 5.749 & 3.444 & 2.779 & 2491 & 2.338 \\
\hline 0.1 & 5.351 & 2.980 & 2.236 & 1.867 & 1.637 \\
\hline 0.2 & 5.060 & 2.653 & 1.874 & 1.478 & 1.230 \\
\hline 0.3 & 4.858 & 2.425 & 1.629 & 1.226 & 0.979 \\
\hline 0.4 & 4.734 & 2.276 & 1.467 & 1.063 & 0.820 \\
\hline 0.5 & 4.682 & 2.194 & 1.371 & 0.964 & 0.724 \\
\hline 0.6 & 4.702 & 2.177 & 1.333 & 0.918 & 0.676 \\
\hline 0.7 & 4.795 & 2.227 & 1.356 & 0.925 & 0.675 \\
\hline 0.8 & 4.970 & 2.357 & 1.451 & 0.997 & 0.730 \\
\hline 0.9 & 5.238 & 2.590 & 1.649 & 1.166 & 0.876 \\
\hline 1.0 & 5.622 & 2.969 & 2.012 & 1.511 & 1.202 \\
\hline
\end{tabular}

Fig. 3. Field distribution for sphere gap with one sphere at earth potential.

and $d$ the gap length. The field strength $E(x)$ at a point on the center line at a distance $x$ from the high-voltage sphere can then be written as

$$
E(x)=e(x / d, d / D)(V / D)
$$

where $V$ is the applied voltage, and $e(x / d, d / D)$ a function for which numerical values are given in Fig. 3. It is seen that the field distribution is nonsymmetrical as well as nonuniform.

The application of (8) to a gap length of $5 \mathrm{~cm}$ is shown in Figs. 4 and 5. The solution can only be found by trial and error. The calculations are time consuming if done by hand, a computer has, therefore, been programmed to carry out the calculations automatically. The calculated breakdown voltage is $136 \mathrm{kV}$ and the IEC standard value [19] is $137 \mathrm{kV}$. It is seen that the breakdown equation is fulfilled for $x=d$, i.e., the avalanche must cross the whole gap length before it leads to breakdown. This type of breakdown is called streamer mechanism I.

For longer gap lengths the field distribution is so nonuniform that $\alpha$ is virtually zero in the mid-gap region. The breakdown equation will in such cases by fulfilled for an avalanche length which is a small fraction of the gap length. This type of breakdown is called streamer mechanism II. This is illustrated in Figs. 6 and 7 for a gap length of $10 \mathrm{~cm}$. The critical avalanche length is here only $1.4 \mathrm{~cm}$. The calculated breakdown voltage is $241 \mathrm{kV}$ and the standard value is $244 \mathrm{kV}$.

Figures 8 and 9 show the calculations for a gap length of $8 \mathrm{~cm}$. The breakdown equation is here fulfilled for $x=1.5$ $\mathrm{cm}$ as well as for $x=8 \mathrm{~cm}$, i.e., the breakdown can follow either mechanism I or mechanism II. The calculated and the standard breakdown voltage are, respectively, 207 and $206 \mathrm{kV}$. For gap lengths shorter than $8 \mathrm{~cm}$ mechanism lower breakdown voltages than mechanism II will be given; for longer gap lengths it is the other way round, as shown in Fig. 10. It is seen that a consequence of the breakdown equation is that the breakdown voltages

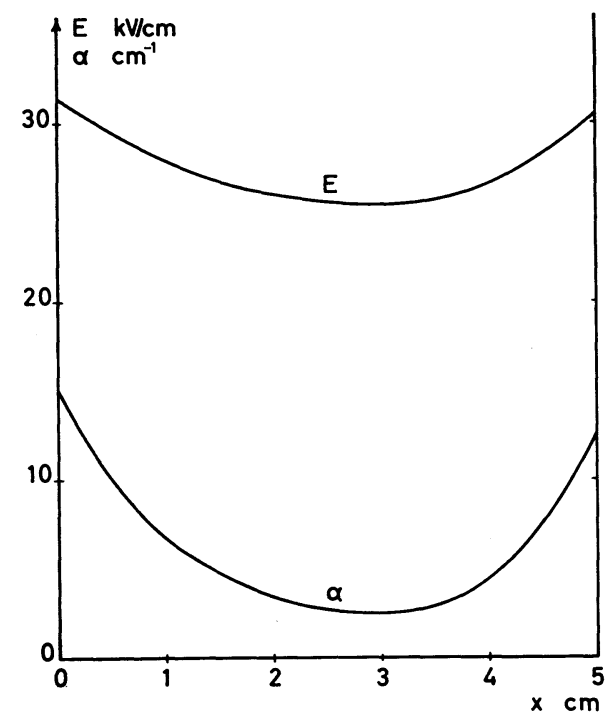

Fig. 4. $D=25 \mathrm{~cm}, d=5 \mathrm{~cm}$; field distribution and Townsend's $\alpha$ for $V=136 \mathrm{kV}$.

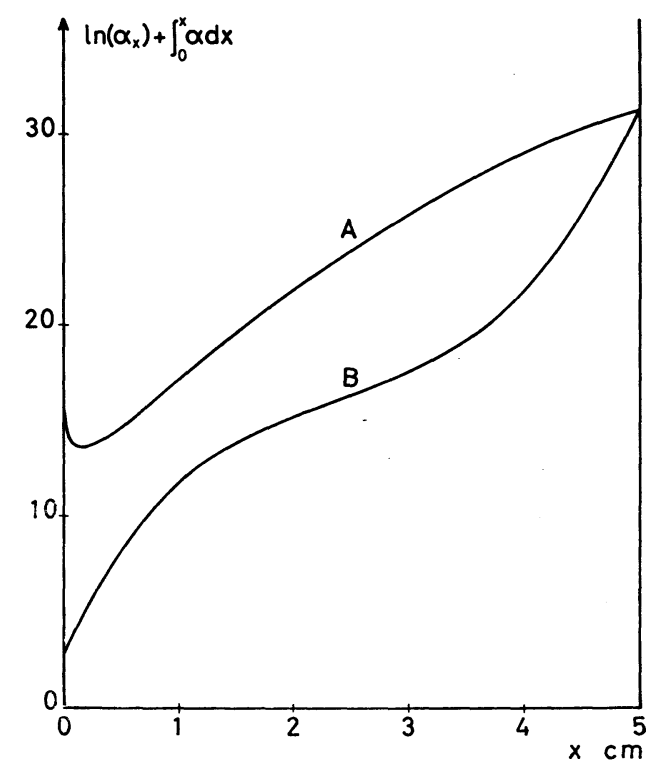

Fig. 5. $D=25 \mathrm{~cm}, D=5 \mathrm{~cm}$; curve A is $g(x)$, and curve B is $\ln \left(\alpha_{x}\right)+\int_{0}^{x} \alpha d x$ for $V=136 \mathrm{kV}$.

should follow two different curves, and that the transition between the two curves should be sharp.

The existence of such a transition is a well established experimental fact [13], [18], [20]-[22]. It was discovered by Toepler [23] and is known as the Toepler discontinuity. Toepler found that the breakdown voltages for a given sphere diameter could be closely matched by two empirical equations, and that the transition between the ranges where these equations could be applied was very sharp. The position of the Toepler discontinuity for $25 \mathrm{~cm}$ diameter spheres has been found experimentally by Claussnitzer [20] and by McMillan [24] to be at a gap length between 7 and $8 \mathrm{~cm}$.

An explanation based on the streamer theory was first given by Meek [25], who suggested that the Toepler discontinuity was caused by a transition between two types 


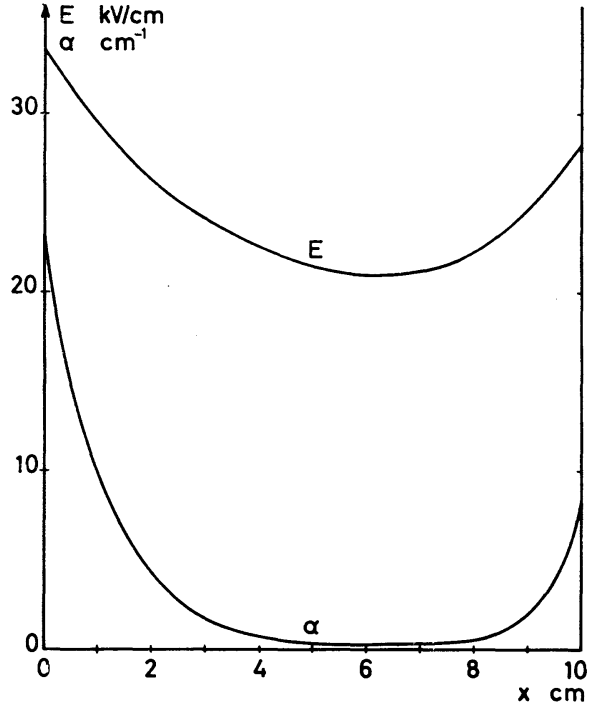

Fig. 6. $D=25 \mathrm{~cm}, d=10 \mathrm{~cm}$; field distribution and Townsend's $\alpha$ for $V=241 \mathrm{kV}$.

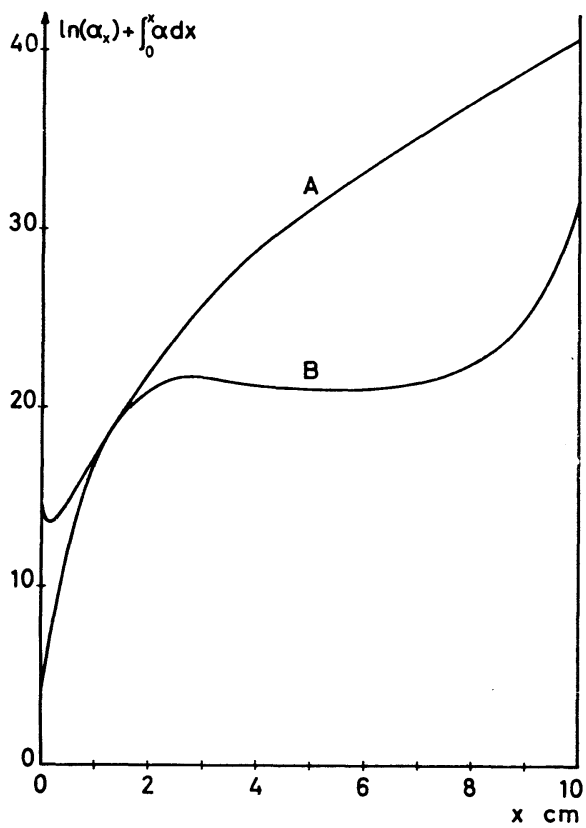

Fig. 7. $D=25 \mathrm{~cm}, d=10 \mathrm{~cm}$; curve A is $g(x)$, and curve B is $\ln \left(\alpha_{x}\right)+\int_{0}^{x} \alpha d x$ for $V=241 \mathrm{kV}$.

of streamer mechanisms. It is seen that Meek's hypothesis combined with the application of (8) can give a detailed quantitative explanation of the Toepler discontinuity.

In a nonsymmetrical field of positive polarity the highfield region will be located near the positive high-voltage electrode. An avalanche leading to breakdown according to mechanism II starts at a suitable point in the gap near the anode, and the critical amplification in the avalanche should be reached when the avalanche head is at the surface of the anode. The starting point of the avalanche is

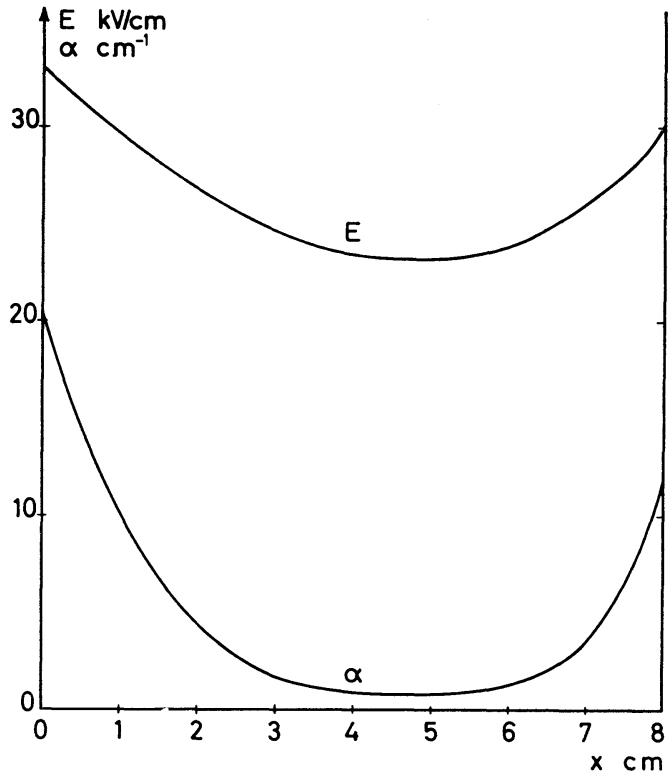

Fig. 8. $D=25 \mathrm{~cm}, d=8 \mathrm{~cm}$; field distribution and Townsend's $\alpha$ for $V=207 \mathrm{kV}$.

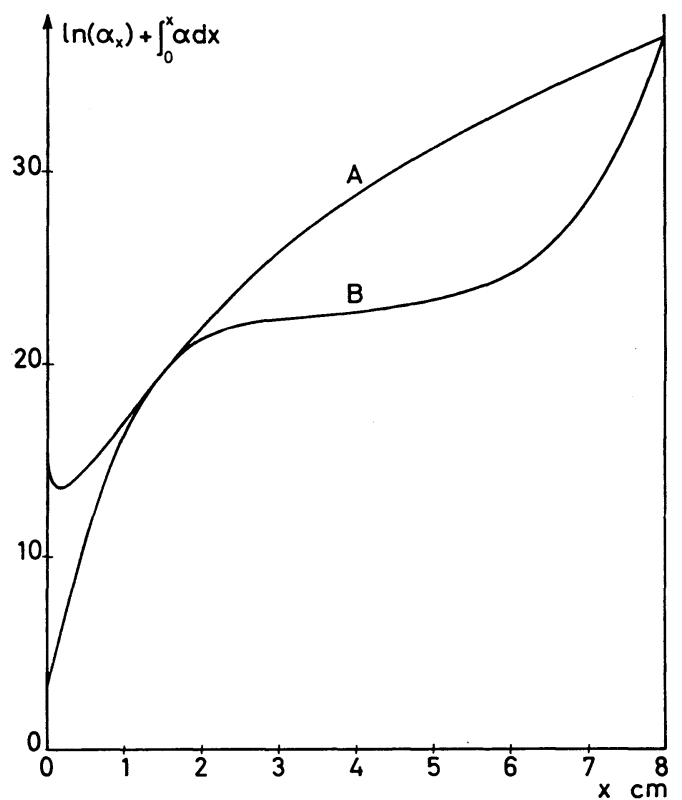

Fig. 9. $D=25 \mathrm{~cm}, d=8 \mathrm{~cm}$; curve $\mathrm{A}$ is $g(x)$ and curve B is $\ln \left(\alpha_{x}\right)+\int_{0}^{x} \alpha d x$ for $V=207 \mathrm{kV}$.

at a distance $x$ from the anode, where $x$ is unknown. If the positive direction of the integration is taken from the anode towards the cathode, the breakdown equation will take the form

$$
\ln \left(\alpha_{0}\right)-\int_{x}^{0} \alpha d x=g(x)
$$

or

$$
\ln \left(\alpha_{0}\right)+\int_{0}^{x} \alpha d x=g(x)
$$




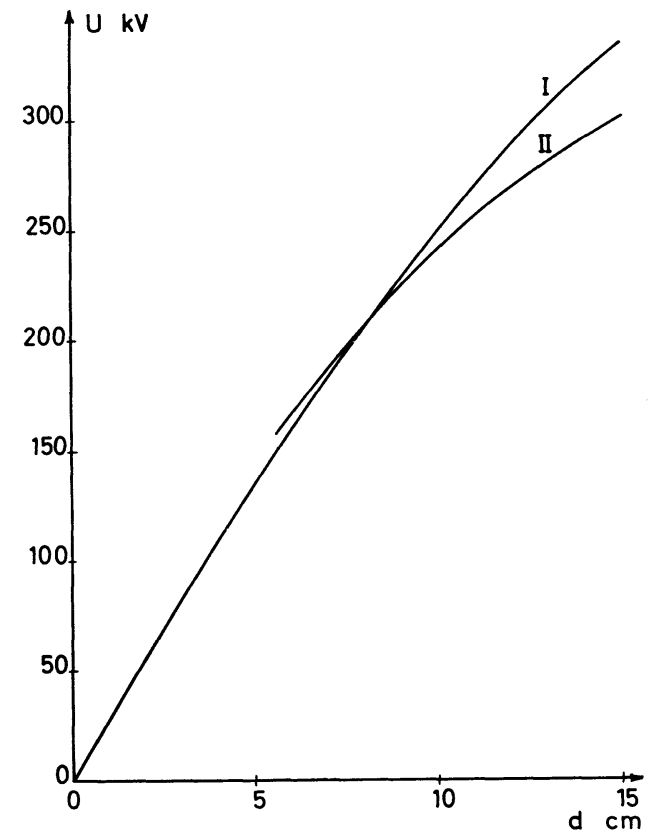

Fig. 10. Calculated breakdown voltages for 25 -cm spheres; negative polarity; (I) and (II) refer to mechanisms I and II.

where $\left(\alpha_{0}\right)$ is the numerical value of $\alpha$ at the surface of the anode, i.e., for $x=0$. The actual procedure is thus the same as for negative polarity, but the results will, of course, be slightly different.

\section{Breakdown in OTher Gases}

So far only breakdown in air has been discussed. The method described can also be applied to other gases, if the necessary fundamental data are available. Experimental studies by Hochberg and Sandberg [26] on the values of $\alpha$ at breakdown in various gases seem to indicate that the function $g(x)$ should be almost independent of the gas if referred to the same pressure and temperature. All that is needed for an application of the breakdown equation would then be a knowledge of Townsend's $\alpha$ as a function of field strength. However, more data are required before this question can be settled.

\section{Conclusion}

Breakdown criteria, such as Townsend's equation or Meek's streamer equation, are of limited use to high-voltage design engineers. In many cases the lack of fundamental data makes their application difficult or impossible, and the results are no better than those obtained from rule of thumb methods. It is, however, possible to formulate a semiempirical quantitative breakdown criterion based on these physical theories. This criterion can be used to correlate breakdown voltages in uniform fields with spark breakdown or corona starting voltages in nonuniform fields of known field distribution. The criterion gives results which are in close agreement with experiments, and it is also capable of showing details in breakdown characteristics such as the Toepler discontinuity for sphere gaps.

\section{REFERENCES}

[1] A. Roth, Hochspannungstechnik. Vienna: Springer-Verlag 1965.

2] F. W. Peek, Dielectric Phenomena in High-Voltage Engineering. New York: McGraw-Hill, 1929.

[3] J. M. Meek and J. D. Craggs, Electrical Breakdown of Gases. Oxford, England: Clarendon Press, 1953.

[4] B. Gänger, Der elektrische Durchschlag von Gasen. Berlin, Germany: Springer-Verlag, 1953.

[5] F. Llewellyn-Jones, Ionization and Breakdown in Gases. New York: Wiley, 1957.

[6] J. D. Cobine, Gaseous Conductors. New York: Dover, 1958.

[7] L. B. Loeb and J. M. Meek, The Mechanism of the Electric Spark. Stanford, Calif.: Stanford University Press, 1941.

[8] H. Raether, "Uber den Aufbau von Gasentladungen," $Z$. fur Physik, vol. 117, pp. 375 and 524, 1941.

[9] - Electron Avalanches and Breakdown in Gases. London, England: Butterworth, 1964.

[10] W. O. Schumann, Elektrische Durchbruchfeldstärke von Gasen. Berlin, Germany: Springer-Verlag, 1923.

[11] D. W. Ver Planck, "Calculation of initial breakdown voltages in air," Trans. AIEE, vol. 60, pp. 99-104, 1941.

[12] J. G. Hutton, "Determination of corona starting voltages for nonuniform fields in air," Trans. AIEE, vol. 66, pp. 1674$1680,1947$.

[13] M. O. Jørgensen, Elektrische Funkenspannungen. Copenhagen, Denmark: Munksgaard, 1943.

[14] A. Pedersen, "Calculation of spark breakdown voltages in air at atmospheric pressure," Appl. Scientific Res. (Holland), vol. B1, p. 299, 1949.

[15] F. H. Sanders, "Measurement of Townsend coefficient for ionization by collision," Phys. Rev., vol. 44, p. 1020, 1933.

[16] Landolt-Börnstein, Physikalish-Chemische Tabellen. Berlin, Germany: Springer-Verlag, 1957, vol. 4, pt. 3, p. 107.

[17] L. V. Bewley, Two-Dimensional Fields in Electrical Engineering. New York: Dover, 1963.

[18] A. Pedersen and S. Vibholm, "Mechanism of impulse voltage breakdown in air between two spheres," Proc. 1966 Internat'l Conf. on Phenomena in Ionized Gases, vol. 1, p. 591, 1966.

[19] "Recommendations for voltage measurement by means of sphere-gaps (one sphere earthed)," Internat'l Electrotechnical Commission, Geneva, Switzerland, pub. 52, 1960.

[20] J. Claussnitzer, "Zur Messung mit Kugelfunkenstrecken," Elektrotech. Z., vol. 57, p. 177, 1936.

[21] W. Dattan, "Zur Eichung von Kugelfunkenstrecken bei Stosspannungen und Normalfrequenz," Elektrotech. Z., vol. 57, pp. 377 and $412,1936$.

[22] E. Hueter, "Uber die Messung des Scheitelwertes technischer Wechselspannungen mittels der Kugelfunkenstrecke," Elektrotech. Z., vol. 57, p. 621, 1936 .

[23] M. Toepler, "Knickstelle im Verlaufe der Anfangspannung," Elektrotech. Z., vol. 53, p. 1219, 1932.

[24] F. O. McMillan, "Polarity limits of the sphere gap," Trans.. $A I E E$, vol. 58 , pp. 56-61, 1939 .

[25] J. M. Meek, "A theoretical determination of breakdown. voltage for sphere-gaps," J. Franklin Inst. vol. 230, p. 229, 1940.

[26] J. M. Meek and J. D. Craggs, op. cit., pp. 263 and 265.

\section{Discussion}

R. E. Voshall (Westinghouse Research and Development Center Pittsburgh, Pa.): Dr. Pedersen's calculations of the breakdown voltage of the sphere gap considering the streamer mechanism is a good approach. Although he points out that photoionization is important to the formation of the streamer, he neglects secondary processes including photoionization and uses an empirical method to calculate $g(x)$ [defined by (8)] from which the breakdown voltage is inferred. This diverts from the physical significance of photoionization. A better approach would be to calculate $g(x)$ in terms of photoionization parameters as well as $\alpha$ (Townsend's first coefficient).

Manuscript received February 17, 1966 
Penney and Voshall ${ }^{1}$ have made measurements of photoionization from a discharge in air and using this data Penney, Nygren, and Voshall ${ }^{2}$ show that photoionization is a plausible secondary mechanism in a Townsend discharge in short gaps. Here a uniform electric field was assumed. The probability of producing an electron in the region of the cathode by ionizing radiation from the initial avalanche was calculated. This probability was found to be approximately one, indicating that the discharge is self-maintaining. Also time lag of breakdown when overvoltage is applied was considered. Using similar techniques, the voltage required to cause the streamer to propagate across a sphere gap in which nonuniform fields exist could be calculated from published data on photoionization and $\alpha$. This voltage is the breakdown voltage. Such a calculation would be a check on Dr. Pedersen's results.

${ }^{1}$ G. W. Penney and R. E. Voshall, "Ionization of a gas by radiation from a discharge," AIEE Trans. (Communication and Electronics), vol. 81, pp. 398-403, January 1963.

${ }^{2}$ G. W. Penney, S. F. Nygren, and R. E. Voshall, "Photoionization as the secondary mechanism in a Townsend breakdown," IEEE Trans. on Communication and Electronics, vol. 83, pp. 203208, March 1964.
A. Pedersen : I thank Dr. Voshall for his interesting suggestions, and agree with him that photoionization should be included in the calculations when considering the physical processes involved in a breakdown. I fear, however, that attempts in this direction may be disappointing because of the very dominating influence on any numerical calculation of Townsend's first ionization coefficient. For the same reason a good agreement between calculated and observed breakdown voltages may not necessarily mean that the assumed breakdown mechanism is correct. When discussing breakdown mechanism, emphasis should be laid upon details in observed breakdown characteristics such as the Toepler discontinuity for sphere gaps rather than upon the actual breakdown voltages.

From an engineering point of view nothing would be gained by including photoionization in the calculations. The numerical results would not be improved, and the actual procedure would be much more complicated.

Manuscript received March 17, 1966.

\title{
Impulse Studies on Distribution Line Construction
}

\author{
H. R. ARMSTRONG, Fellow, ieee, H. O. STOELTING, SENior Member, IEeE, AND \\ E. F. VEVERKA, MEMBER, IEEE
}

\begin{abstract}
Electric utilities are striving to improve the appearance of distribution lines and simultaneously reduce lightning outages. Unfortunately, many suggested departures from crossarm construction that improve appearance reduce the impulse insulation strength of the lines, causing more, rather than fewer, tripouts.

Considerable exploratory work has been done on the insulation characteristics of subtransmission and transmission lines. In contrast, very little data is available on the impulse insulation strength of the combinations of insulators, wood, and new materials, such as fiberglass reinforced plastics that comprise distribution line construction.

Laboratory studies of 1) impulse insulation strengths, 2) surge impedance and coupling factors, 3 ) self-clearing of fault arcs, and 4) line impulse protection, as related to open wire distribution construction are reported. These tests, sponsored by The Detroit Edison Company, were conducted at the Thomas A. Edison Laboratories of Line Material Industries, McGraw-Edison Company.
\end{abstract}

\section{INTRODUCTION}

\section{Test Arrangements}

A ONE-HALF mile long wood-pole line was constructed; one end terminating at the high voltage laboratory, the other at the short circuit test station. A ground reference plane was established using a bare conductor on the ground beneath the line, connected to the laboratory grounds at each end, and to ground rods at each pole. Location of the laboratories in open farm country made this line arrangement possible.
Various line configurations that were tested are shown in Fig. 1. Figure 1(a) shows the shielded crossarm construction. The armless construction of Fig. 1(b) consists of fiberglass reinforced plastic (FRP) brackets, post insulators, and bare conductors. The spacerless construction, Fig. 1(c), utilized both metal and insulating pole top brackets, post insulators, and polyethylene insulated cable. The spacer cable, Fig. 1(d), was rated $5 \mathrm{kV}$ with polypropylene spacers and polyethylene insulated cable.

Impulse insulation tests were made in the high voltage laboratory on components mounted with various configurations on stub poles. A typical test setup is shown in Fig. 2. In this particular test, the entire construction was suspended from an overhead crane. Impulse tests with the line energized, for fault clearing and line protection investigations, were conducted with the fault arc initiated under the line immediately outside of the high voltage laboratory. The line was energized through a transformer.

Paper 31 TP 66-93, recommended and approved by the Transmission and Distribution Committee of the IEEE Power Group for presentation at the IEEE Winter Power Meeting, New York, N.Y., January 30-February 4, 1966. Manuscript submitted November 1, 1965; made available for printing December 3, 1965.

H. R. Armstrong is with the Detroit Edison Company, Detroit, Mich.

H. O. Stoelting and E. F. Veverka are with Line Material Industries, McGraw-Edison Company, Milwaukee, Wis. 